\title{
Indução de resistência a Colletotrichum sp. em Heliconia psittacorum x sparthocircinata cv. Golden Torch cultivada em ambiente sombreado e pleno sol
}

João Vitor da Silva Alves ${ }^{1} \oplus$, Mayara Pereira Coelho ${ }^{1}$, Fellipe Lima Bertan ${ }^{1}$, Dayane Castro Silva ${ }^{2}$, Vanessa Costa da Silva ${ }^{1}$, Micheli Tonoli Chiamulera ${ }^{1}$, Ilio Fealho de Carvalho ${ }^{1} \mathbb{0}$, Celice Alexandre Silva ${ }^{1} \oplus$, Dejânia Vieira de Araújo ${ }^{1} \oplus$

${ }^{1}$ Universidade do Estado de Mato Grosso (UNEMAT), Rodovia MT 358 Km 7, CEP 78300-000, Jardim Aeroporto, Tangará da Serra, Mato Grosso, Brasil. ${ }^{2}$ Universidade Federal de Mato Grosso (UFMT), Av. Fernando Corrêa da Costa, 2367, CEP 78060-900, Boa Esperança. Cuiabá, Mato Grosso, Brasil.

Autor para correspondência: João Vitor da Silva Alves (joaovitor_fnt@hotmail.com)

Data de chegada: 21/05/2020. Aceito para publicação em: 20/08/2020.

$10.1590 / 0100-5405 / 238457$

\section{RESUMO}

Alves, J.V.S.; Coelho, M.P.; Bertan, F.L.; Silva, D.C.; Silva, V.C.; Chiamulera, M.T.; Carvalho, I.F.; Silva, C.A.; Araújo, D.V. Indução de resistência a Colletotrichum sp. em Heliconia psittacorum x sparthocircinata cv. Golden Torch cultivada em ambiente sombreado e pleno sol. Summa Phytopathologica, v.46, n.4, p.320-326, 2020.

Entre as principais doenças que acometem o gênero Heliconia, destaca-se a antracnose (Colletotrichum sp.) interferindo na produção, no desenvolvimento e na qualidade das flores. Como alternativa de manejo tem-se a indução de resistência utilizando indutores bióticos e abióticos. Dessa forma, o presente estudo teve por objetivo testar indutores de resistência no controle da antracnose em genótipo de Heliconia psittacorum $\mathrm{x}$ sparthocircinata $\mathrm{cv}$. Golden Torch cultivada em ambiente sombreado e a pleno sol e determinar a ativação de enzimas relacionadas à patogênese. Foram utilizados dois indutores de resistência usados em conjunto, um indutor biótico Bacillus subtilis e um abiótico o produto Acibenzolar-smetílico (ASM). O delineamento experimental empregado foi de blocos casualizados, num esquema fatorial $2 \times 2$ (duas condições de cultivo [telado nível de sombreamento $(50 \%)$ e a pleno sol] $\mathrm{x}$ duas condições de indução de resistência [com e sem aplicação de indutores]), com três parcelas subdivididas de $3 \times 3 \mathrm{~m}$, contendo 9 repetições com 2 perfilhos em cada subparcela para avaliação da severidade da doença e 5 perfilhos em cada subparcela para determinação das proteínas relacionadas à patogênese (PRP's). Para a avalição da produtividade foi determinada uma área de $2 \times 2 \mathrm{~m}$ dentro de cada subparcelas. As coletas para análise enzimática de peroxidase, $\beta$-1,3-glucanase e proteínas totais iniciaram 24 horas após uma aplicação de indutores e foram coletadas nos tempos de 24, 48, 72, 96 e 120 horas após o tratamento. Os indutores de resistência usados em conjunto atuaram como elicitores na atividade da peroxidase e $\beta-1,3$ glucanase, além disso, as plantas cultivadas no ambiente sombreado apresentaram menor severidade $\mathrm{e}$ menor Área Abaixo da Curva de Progresso da Severidade (AACPS) quando comparadas com as plantas cultivadas a pleno sol. Nas subparcelas com tratamento os indutores reduziram a severidade da doença, mas não houve interferência para AACPS. Os indutores proporcionaram incrementos na produtividade de hastes florais, sendo de $68,65 \%$ nas plantas cultivadas em ambiente sombreado e $26,86 \%$ nas cultivadas a pleno sol.

Palavras-chave: antracnose, peroxidase, $\beta-1,3$ glucanase, floricultura.

\section{ABSTRACT}

Alves, J.V.S.; Coelho, M.P.; Bertan, F.L.; Silva, D.C.; Silva, V.C.; Chiamulera, M.T.; Carvalho, I.F.; Silva, C.A.; Araújo, D.V. Induction of resistance to Colletotrichum sp. inHeliconia psittacorum x sparthocircinata cv. Golden Torch grown in shade and full-sun environment. Summa Phytopathologica, v.46, n.4, p.320-326, 2020.

Among the major diseases that affect the genus Heliconia, anthracnose (Colletotrichum sp.) is highlighted for interfering in the production, development and quality of flowers. As a management alternative, resistance induction using biotic and abiotic inducers has been adopted. Thus, the present study aimed to test resistance inducers on the control of anthracnose in the genotype Heliconia psittacorum x sparthocircinata cv. Golden Torch grown in shade and full-sun environment, as well as to determine the activation of pathogenesis-related enzymes. Two resistance inducers were used together: a biotic inducer, Bacillus subtilis, and an abiotic inducer, Acibenzolar-s-methyl (ASM). Experimental design was in randomized blocks, in a $2 \times 2$ factorial arrangement (two cultivation conditions [shade-level screen (50\%) and fullsun] $\mathrm{x}$ two resistance induction conditions [with and without application of inducers]), including three subdivided plots of $3 \times 3 \mathrm{~m}$. Each subplot contained
9 replicates and 2 tillers for assessing the disease severity plus 5 tillers for determining the pathogenesis-related proteins (PRP's). To assess productivity, an area of $2 \times 2 \mathrm{~m}$ was determined within each subplot. Samplings for analysis of peroxidase, $\beta$-1,3-glucanase and total proteins started 24 hours after the application of inducers and were performed at 24, 48, 72, 96 and 120 hours after treatment. The resistance inducers used together acted as elicitors for the activity of peroxidase and $\beta-1,3$ glucanase; in addition, plants grown in the shade environment showed less severity and smaller Area Under the Disease Progress Curve (AUDPC) when compared to plants grown in full sun. In treated subplots, the inducers reduced the disease severity, but there was no interference for AUDPC. The inducers increased the productivity of flower stems, which reached $68.65 \%$ in plants grown in shade environment and $26.86 \%$ in plants grown in full sun.

Keywords: anthracnose, peroxidase, $\beta-1,3$ glucanase, floriculture.

O gênero Heliconia, único pertencente à família Heliconiaceae, apresenta destaque no ramo da floricultura por conter inflorescências com brácteas em diversas formas e cores, exuberância, durabilidade pós-colheita e elevado atributo ornamental (8).

No estado de Mato Grosso, a distribuição e diversidade desse gênero é ampla, uma vez que a região apresenta condições climáticas favoráveis para o cultivo a pleno sol ou meia sombra (19). O clima favorável, também propicia a disseminação de fungos fitopatogênicos que provocam inúmeras doenças, comprometendo as vias reprodutoras, inflorescências, flores, folhas e pseudocaules (29).

Entre as doenças mais importantes associadas ao gênero Heliconia, destaca-se a antracnose causada pelos fungos do gênero Colletotrichum. Essa doença provoca danos em folhas e inflorescências, com manchas de coloração marrom e pequenos pontos escuros que vão coalescendo até necrosar toda a inflorescência (20).

Uma alternativa no manejo de doenças fúngicas é a indução de 
resistência, sendo uma importante estratégia para reduzir a severidade da doença a baixos custos e sem efeitos adversos sobre o meio ambiente (6).

$\mathrm{Na}$ indução de resistência, dependendo da rota metabólica ativada a mesma pode ser classificada como Resistência Sistêmica Adquirida (RSA), que envolve o acúmulo de Proteínas Relacionadas à Patogênese (PRPs) como mecanismo de defesa da planta, tendo como rota de sinalização o ácido salicílico. Por outro lado, quando a rota de sinalização está associada ao jasmonato e etileno a resistência é denominada como Resistência Sistêmica Induzida (RSI), onde não há o acúmulo de PRPs, sendo o eliciador geralmente um micro-organismo não patogênico (18).

Os indutores de resistência podem ser de origem bióticos e abióticos. Os indutores bióticos são organismos vivos, ou partes dos mesmos, que proporcionam processos de defesa, com ação sistêmica ou localizada nos vegetais. Os indutores abióticos podem ser moléculas sintéticas que simulem o sinal do patógeno, ativando genes relacionados à defesa, aumento na produção de metabólitos secundários como compostos fenólicos, fitoalexinas e o ácido salicílico (4).

Diante desta perspectiva, a presente pesquisa teve como objetivo testar indutores de resistência biótico e abiótico em Heliconia psittacorum x sparthocircinata cv. Golden Torch a Colletotrichum sp. em plantas cultivadas em ambiente sombreado, assim como avaliar os seus efeitos sobre a produtividade de hastes florais.

\section{MATERIAL E MÉTODOS}

O trabalho foi conduzido no Banco de Germoplasma de Flores Tropicais da Universidade do Estado de Mato Grosso Carlos Alberto Reyes Maldonado (UNEMAT), Campus Universitário Professor Eugênio Carlos Stieller (14³9'53"S e 57²5’46”'W).

Foi selecionado o acesso 22 da coleção do BAG de flores tropicais (Heliconia psittacorum x sparthocircinata cv. Golden Torch). O delineamento experimental empregado foi de blocos casualizados, num esquema fatorial $2 \times 2$ (duas condições de cultivo [telado nível de sombreamento $(50 \%)$ e a pleno sol] x duas condições de indução de resistência [com e sem aplicação de indutores]) com três parcelas subdivididas de $3 \times 3 \mathrm{~m}$, contendo 9 repetições com 2 perfilhos em cada subparcela para avaliação da severidade da doença e 5 perfillhos em cada subparcela para determinação das proteínas relacionadas à patogênese (PRP's).

Foi utilizado um indutor biótico, composto por Bacillus subtilis, e um indutor abiótico, composto por Acibenzolar-S-methyl, aplicados juntos. Os tratamentos consistiram em T0 - testemunha (sem aplicação de indutores) e T1 - indutor biótico (Bacillus subtilis $1 \times 10^{9} \mathrm{UFC} \mathrm{mL}^{-1}$ ) + indutor abiótico (Acibenzolar-S-methyl [ASM] 0,4 $\mathrm{gL}^{-1}$ ).

Nas parcelas que receberam os tratamentos, os indutores foram aplicados no início do estádio vegetativo com reaplicações a cada 15 dias até o pleno desenvolvimento reprodutivo, encerrando-se quando as hastes florais estavam totalmente formadas e as brácteas em ponto de colheita, totalizando oito aplicações.

Não houve inoculação do patógeno agente causal da antracnose (Colletotrichum sp.), tendo em vista que a pesquisa foi realizada no Banco de Germoplasma de Flores Tropicais, onde as espécies presentes ainda estão em estudo, diante disso, a doença ocorreu de forma natural.

Análise da Severidade da antracnose

A severidade da doença foi avaliada durante todo o desenvolvimento da cultura até a colheita em intervalos de 14 dias (duas semanas). Foram atribuídas notas por meio da escala proposta por Abreu (1) adaptada, sendo nota 1 - plantas assintomáticas; nota 2 - 15\% da superfície foliar com sintomas, nota 3 - plantas com $16 \%$ a $45 \%$ da superfície foliar com sintomas e nota 4 - plantas com mais de $45 \%$ da superfície foliar com sintomas. Para avaliação da severidade da doença, foi selecionada a folha localizada no terço médio.

Os resultados das variáveis severidade e Área Abaixo da Curva de Progresso da Severidade da Doença (AACPS), foram submetidos à análise de variância e as médias comparadas utilizando-se o teste de Scott-Knott, a 5\% de probabilidade utilizando o software Sisvar $5.6(10)$.

As coletas de amostras para análise enzimática de peroxidase, $\beta$-1,3-glucanase e proteínas totais iniciaram 24 horas após uma aplicação de indutores nos períodos vegetativos e reprodutivos, as mesmas ocorreram pela manhã, entre $6 \mathrm{~h}$ e $7 \mathrm{~h}$. Foram realizadas cinco coletas nos tempos de 24, 48, 72, 96 e 120 horas após o tratamento (HAT).

Após a coleta, as folhas e inflorescências foram imediatamente colocadas em envelopes de papel alumínio e imersas em $\mathrm{N}_{2}$ líquido e posteriormente armazenadas em ultra freezer a $-80{ }^{\circ} \mathrm{C}$ até a realização do ensaio enzimático.

\section{Atividade de peroxidase e $\beta-1,3$ glucanase}

O extrato enzimático para determinar a atividade de peroxidase e $\beta$-1,3- glucanase foi obtido pela maceração de $0,75 \mathrm{~g}$ de folhas e brácteas em $\mathrm{N}_{2}$ líquido, seguido de homogeneização em $3 \mathrm{~mL}$ da solução de extração composto de tampão de acetato de sódio $20 \mathrm{mM}(\mathrm{pH} 5,0)$. O homogeneizado foi centrifugado a $9.000 \mathrm{~g}$ (giros) por 5 minutos a temperatura ambiente e o sobrenadante obtido foi utilizado para as análises [adaptado de Gurgel et al. (13)].

Para a determinação da atividade de peroxidases foram adicionados em tubo de ensaio (quadruplicata) $25 \mathrm{uL}$ de guaiacol 0,02M, $250 \mathrm{uL} \mathrm{de}$ peróxido de hidrogênio $0,38 \mathrm{M} \mathrm{e} 1 \mathrm{~mL}$ de tampão de acetato de sódio $0,2 \mathrm{M}(\mathrm{pH} 5,2)$ e $25 \mathrm{uL}$ do extrato enzimático. Para o branco, o extrato enzimático foi substituído pelo mesmo volume de água destilada. As leituras de absorbância foram realizadas em espectrofotômetro Femto a $470 \mathrm{~nm}$, em intervalos de um minuto durante três minutos [adaptado de Gurgel et al. (13)].

A atividade de $\beta$-1,3-glucanase foi determinada por meio dos açúcares redutores liberados pela hidrólise da laminarina (29). Em tubos de ensaio (quadruplicata) foram adicionados $10 \mu \mathrm{L}$ do extrato enzimático, $40 \mu \mathrm{L}$ de tampão acetato de potássio $0,1 \mathrm{M}(\mathrm{pH} 4.8)$ e 40 $\mu \mathrm{L}$ de laminarina $(15 \mathrm{mg} / \mathrm{mL})$. $\mathrm{Na}$ amostra controle, foi adicionado $1 \mu \mathrm{L}$ água destilada no lugar do extrato enzimático, posteriormente os mesmos foram incubados a $40^{\circ} \mathrm{C}$ por 60 minutos. Após, foram adicionados $4 \mathrm{~mL}$ de solução hidrazida do ácido $p$ hidroxibenzoico - HAPHB. Em seguida, essa mistura foi aquecida a $100^{\circ} \mathrm{C}$ durante 5 minutos e posteriormente, resfriada em banho de gelo [adaptado de Gurgel et al. (12)]. As leituras espectrofotométricas foram realizadas a $410 \mathrm{~nm}$ e comparadas com os padrões de glicose. A quantidade de açúcares redutores formados foi quantificada pela curva padrão de concentrações de glicose ( $Y=0,1716 \mathrm{X}-0,0104)$, onde $\mathrm{Y}$ é a absorbância a $410 \mathrm{~nm}$ e X a concentração de açúcares redutores (mg) e os resultados expressos em mg de glicose. $\mathrm{min}^{-1} \mathrm{mg}^{-1}$ de proteína.

\section{Proteína total}

$\mathrm{Na}$ determinação de proteína total usou-se o método de Bradford (7). Foram adicionados aos tubos de ensaio (quadruplicatas) $100 \mathrm{uL}$ 


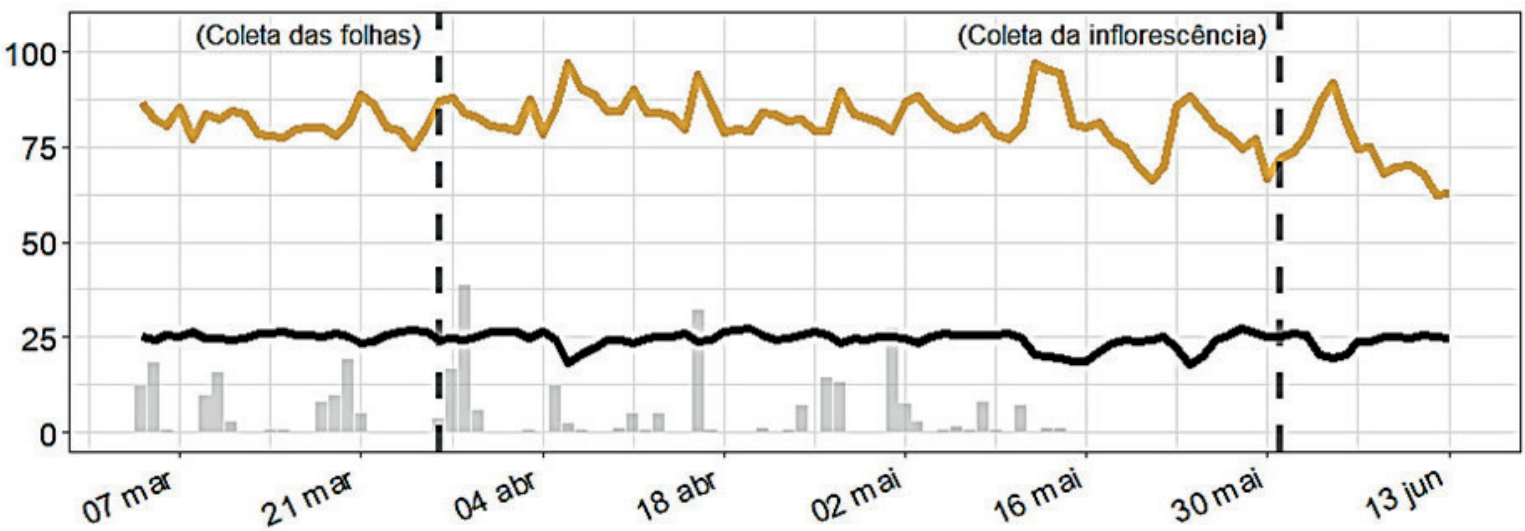

Figura 1. Precipitação (mm), Temperatura Média $\left({ }^{\circ} \mathrm{C}\right)$ e Umidade Relativa do Ar $(\%)$ monitorada de março a junho de 2019 , período de execução do experimento. As linhas pontilhadas no gráfico indicam o momento de coleta no período vegetativo e reprodutivo respectivamente.

do extrato enzimático e $1 \mathrm{~mL}$ do reagente de Bradford. Em seguida, a solução foi incubada por 15 minutos à temperatura ambiente, fez-se a leitura a $595 \mathrm{~nm}$ em espectrofotômetro U.V. A curva-padrão utilizada foi proposta por Silva (24) por meio da equação: $y=15,05 x+0,0003$ $\left(\mathrm{R}^{2}=0,9919\right)$ e os resultados de proteína total expressos em miligramas por $\mathrm{mL}$.

\section{Monitoramento dos dados climáticos}

Foram monitorados os dados de Precipitação, Temperatura e Umidade Relativa durante a condução do experimento (Figura 1). Os dados foram fornecidos pelo Laboratório de Agrometeorologia do Centro Tecnológico de Geoprocessamento e Sensoriamento Remoto - CETEGEO - SR, da Universidade do Estado de Mato Grosso UNEMAT.

\section{Produtividade de hastes florais}

Para a avalição da produtividade foi determinada uma área de $2 \times 2 \mathrm{~m}$ dentro de cada subparcela, na qual foi quantificado o total de hastes que apresentavam o ponto de colheita (quando apresentavam de duas a três brácteas abertas). A produtividade total das subparcelas foram em números de hastes florais por hectare.

\section{RESULTADOS E DISCUSSÃO}

Houve diferença significativa $(\mathrm{p} \leq 0,05)$ em relação à condição de cultivo para as variáveis Severidade e Área Abaixo da Curva de Progresso da Severidade da Doença (AACPS), houve também significância para aplicação de indutores na variável severidade (Tabela 1). Analisando a condição de cultivo, percebeu-se que as plantas cultivadas no ambiente sombreado apresentaram menor severidade e menor AACPS (Tabela 2), quando comparadas com as plantas cultivadas a pleno sol.

Para que as doenças se estabeleçam é necessária a interação entre patógeno $\mathrm{x}$ hospedeiro sob influência do ambiente. Neste estudo houve pouca precipitação $(\leq 25 \mathrm{~mm})$, mesmo as plantas sendo irrigadas três vezes por semana e com umidade relativa do ar acima de $60 \%$ (Figura 1), a germinação de conídios pode ter sido dificultada e consequentemente reduziu a expressão da doença.
A antracnose (Colletotrichum spp.) em flores tropicais é favorecida durante o período chuvoso, o qual é ideal para o seu desenvolvimento, além disso, temperatura e umidade são essenciais para a progressão da doença que pode afetar folhas, flores, inflorescências, pseudocaules e rizomas (29).

Ao observar a curva de progresso da doença, foi possível verificar que nas plantas que receberam os indutores na condição de sombreamento (Figura 2A), a severidade da doença progrediu menos ao longo do experimento. A partir dos 108 dias de avaliação houve uma redução (5\%) nas plantas que receberam os tratamentos com indutores.

Tabela 1. Análise de variância de severidade (\%) e AACPS da antracnose em Heliconia psittacorum x sparthocircinata cv. Golden Torch.

\begin{tabular}{cccc}
\hline \multirow{2}{*}{ FV } & GL & \multicolumn{2}{c}{ QM } \\
\cline { 3 - 4 } & 8 & Severidade & AACPS \\
\hline Bloco & 1 & $3,215^{* *}$ & 126349,55 \\
Condição (C) & 1 & $1,64^{*}$ & $410156,25^{* *}$ \\
Indutor (I) & 1 & $0,28^{\text {ns }}$ & $44589,50^{\text {ns }}$ \\
CxI & 24 & 0,23 & 120889,28 \\
Erro & - & 3,17 & 2206,59 \\
Média Geral & - & 15,19 & 15,76 \\
\hline CV & & $1 \%$ &
\end{tabular}

${ }^{\text {ns }}$ Não significativo, $* *$ Significativo a $1 \%$ de probabilidade de erro e *Significativo a $5 \%$ de probabilidade de erro, pelo Teste $\mathrm{F}$.

Tabela 2. Severidade (\%) e AACPS da antracnose em Heliconia psittacorum x sparthocircinata cv. Golden Torch, em diferentes condições de cultivo.

\begin{tabular}{ccc}
\hline Condição & (\%) Severidade & AACPS \\
\hline Sombreado & a 87,2 & a 2008,68 \\
Pleno Sol & b 47,3 & b 2404,51 \\
\hline
\end{tabular}

Médias com mesma letra minúscula na coluna, não diferem entre si pelo teste de Scott-Knott a 1\% de probabilidade. 


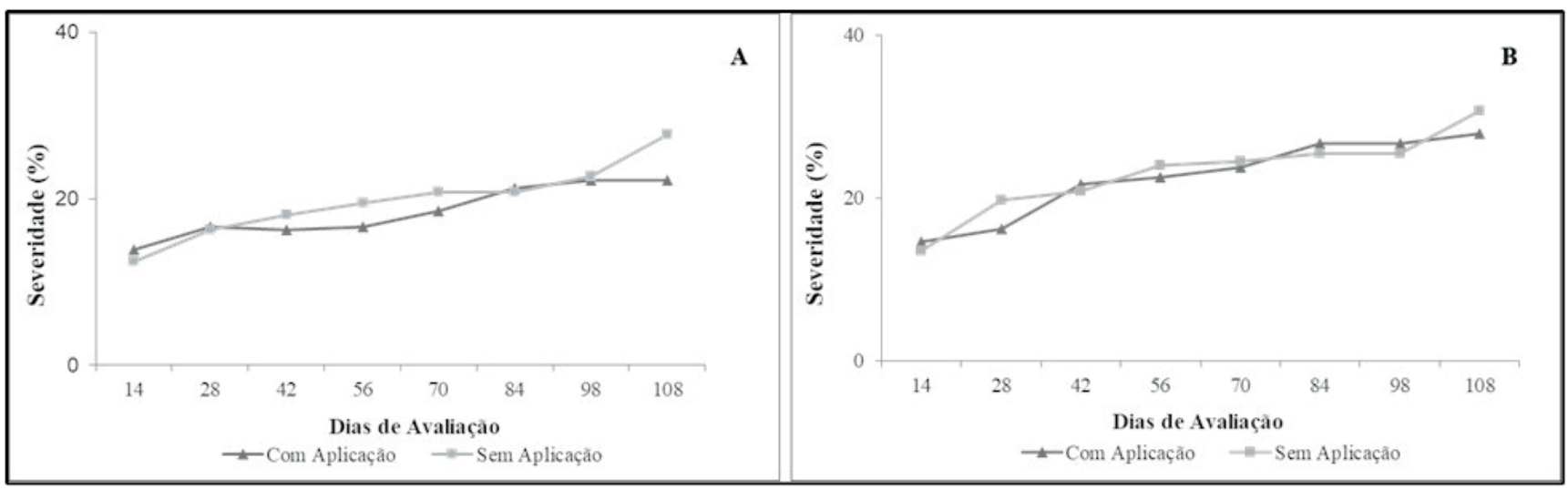

Figura 2. Curva de progresso da severidade da antracnose em Heliconia psittacorum x sparthocircinata cv. Golden Torch cultivadas em ambiente sombreado (A) e a pleno sol (B), tratadas com ASM + Bacillus subtilis e planta controle.

Para as plantas cultivadas a pleno sol (Figura 2B), foi possível observar que houve um acréscimo da severidade da doença nas plantas não tratadas com os indutores, contudo, a partir dos 108 dias de avaliação, as plantas tratadas com os indutores tiveram uma redução da severidade (3\%) quando comparadas com as plantas sem indutores.

A menor severidade e AACPS observadas no ambiente sombreado pode estar associado ao fato de o ambiente protegido possibilitar uma alteração no microclima, proporcionando a restrição de água livre sobre as folhas, fator primordial para desencadear o início das infecções fúngicas (11).

Em estudo realizado por Poletto (21), ao analisar a severidade da doença causada por Fusarium spp. em mudas de erva - mate (Ilex paraguariensis) sob diferentes níveis de sombreamento, verificou-se que quanto maior o nível de sombreamento, menor foi a severidade da doença.

Os indutores de resistência (Bacillus subtilis + Acibenzolar-Smethyl [ASM]) diminuíram a severidade da antracnose nas subparcelas que receberam o tratamento (Tabela 3), porém para a ACPS, os indutores igualaram a testemunha (sem aplicação). Essa redução pode estar associada à ativação de mecanismos de defesa, como por exemplo, de enzimas relacionadas à patogênese, pois no processo de indução o contato do eliciador com a planta faz com que os genes de resistência sejam ativados e se expressam para a síntese dos componentes de resistência (27).

Os resultados encontrados nesta pesquisa assemelham-se aos observados por Silva (23), que ao utilizar ASM + Bacillus subtilis obteve resultado expressivo na redução da antracnose em $H$. psittacorum cv. Golden Torch inoculada com Colletotrichum sp., em condições de ambiente controlado, diferente do presente estudo que foi realizado a campo. A autora ainda verificou a atividade de peroxidase durante sete dias de avaliação após a aplicação dos indutores, a mesma observou maiores picos de peroxidase no segundo, quinto e sexto dia de análise, evidenciando a associação entre a redução da severidade da antracnose e ativação das proteínas relacionadas à patogênese.

Em relação à quantificação de peroxidase em folhas de Heliconia cv. Golden Torch foi observado nas plantas tratadas com os indutores na condição de cultivo de sombreamento (

3A), os maiores picos de ativação às 48 e 96 horas após o tratamento (HAT). Nas plantas cultivas a pleno sol (Figura 3B), não houve efeitos dos indutores sobre a atividade de peroxidase, que obteve maiores concentrações nas plantas controle às 48 e 96 (HAT).

A atividade de peroxidase nas inflorescências de Heliconia cv. Golden Torch cultivada em ambiente sombreado (Figura 3C) apresentou
Tabela 3. Severidade (\%) e AACPS da antracnose em Heliconia psittacorum x sparthocircinata cv. Golden Torch, tratadas com Bacillus subtilis + Acibenzolar-S-methyl [ASM] e plantas controle.

\begin{tabular}{ccc}
\hline Indutor & (\%) Severidade & AACPS \\
\hline Com & a 97,2 & a $2.174,34$ \\
Sem & b 40,3 & a $64,2.242$ \\
\hline
\end{tabular}

Médias com mesma letra minúscula na coluna, não diferem entre si pelo teste de Scott-Knott a 5\% de probabilidade.

maiores picos de ativação às 24, 48 e 120 HAT a partir da aplicação dos indutores. Nas inflorescências cultivadas a pleno sol (Figura 3D), não houve efeitos dos indutores na atividade de peroxidase.

$\mathrm{O}$ alto pico de peroxidase nas plantas do ambiente sombreado indicou a ativação dos mecanismos de defesa da planta, mesmo esses sendo ativados tardiamente, tal fato evidencia que nas condições do estudo as plantas expressaram Resistência Sistêmica Adquirida (RSA). Picos de peroxidase também foi encontrado por Silva (23) em H. psittacorum cv. Golden Torch, sendo o tempo de 48 h, o de maior atividade da proteína.

A resposta tardia na atividade de peroxidase nas plantas durante $o$ estádio reprodutivo, pode estar associada com a produção de compostos voláteis ou de metabólitos gerados anteriormente à síntese da proteína (3).

O pico de atividade da peroxidase nas plantas a pleno sol sem tratamento pode ter sido influenciada pelas condições de exposição excessiva à luminosidade, pois a mesma pode ser alterada mediante as condições de estresse, seja biótico ou abiótico (9). Além disso, a aplicação dos indutores pode ter amenizado os estresses em que as plantas estavam submetidas, tendo em vista que a bactéria Bacillus subtilis faz parte do grupo de bactérias promotoras de crescimento, as mesmas aumentam a taxa fixação de nitrogênio, solubilização de nutrientes, síntese de fitormônios e melhoria das condições do solo (15).

Resultado semelhante a este trabalho foi encontrado por Valderrama et al. (26), ao observarem redução na atividade de peroxidase em Mallus comunis após ser submetida a diferentes condições térmicas.

Para atividade da $\beta$-1,3-glucanase, nas plantas do ambiente sombreado (Figura 4A), pôde-se observar que a aplicação dos indutores promoveu a indução de resistência, pois durante todas as coletas constatou-se que houve ativação da proteína, destacando o período de 48 HAT com maior pico e 120 HAT o menor pico. Comportamento diferente ocorreu nas plantas a pleno sol (Figura 4B), onde os picos de ativação para a $\beta$-1,3-glucanase foram em 48, 96 e 120 HAT nas 

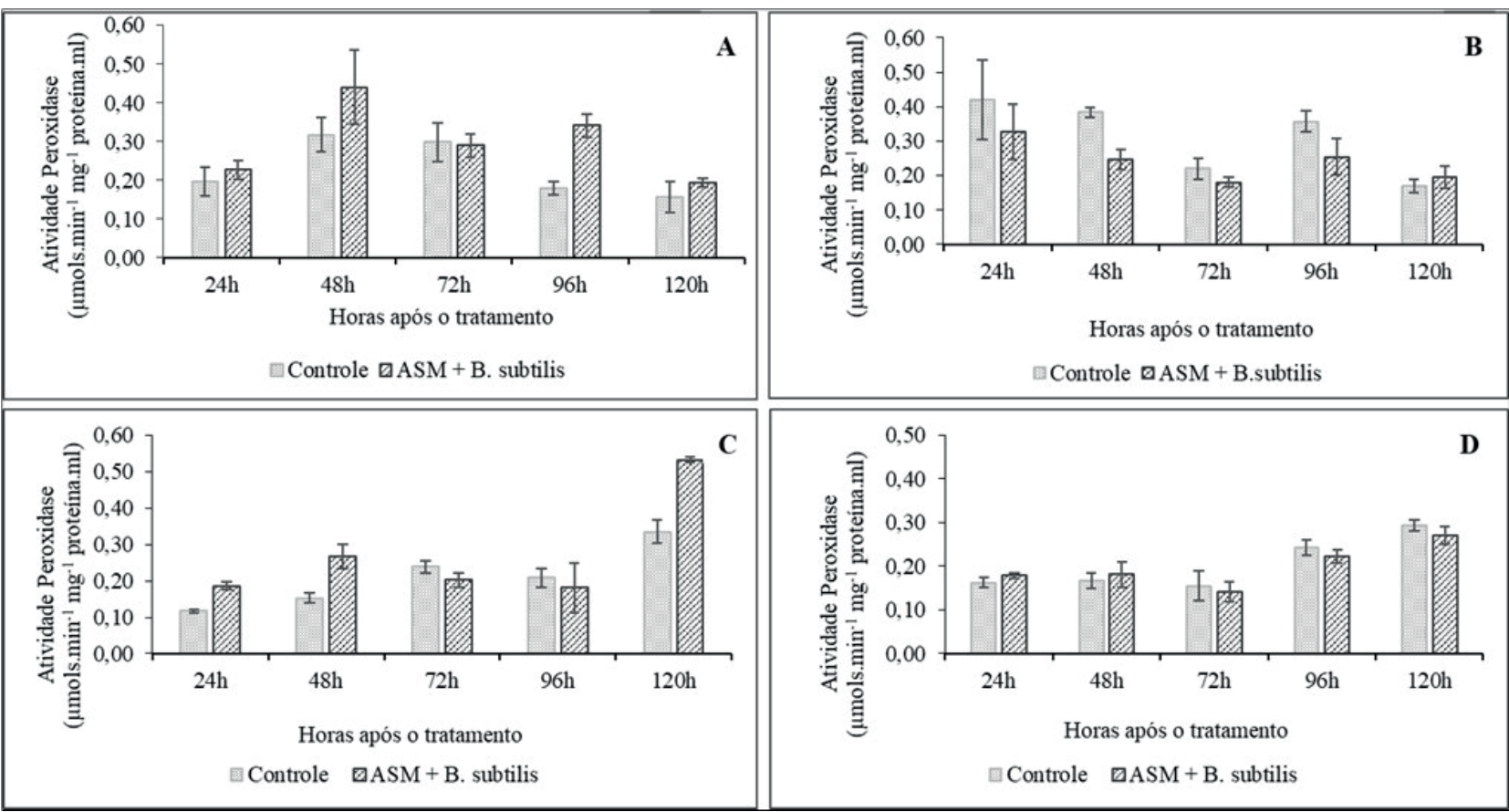

Figura 3. Atividade de peroxidase em folhas de Heliconia psittacorum x sparthocircinata cv. Golden Torch cultivadas em sombreamento (A) e a pleno sol (B) e inflorescências cultivadas em sombreamento (C) e a pleno sol (D), tratadas com ASM + Bacillus subtilis e planta controle, coletadas com 24, 48, 72, 96 e 120 horas após o tratamento (HAT). As barras indicam o desvio padrão para as quadruplicatas.
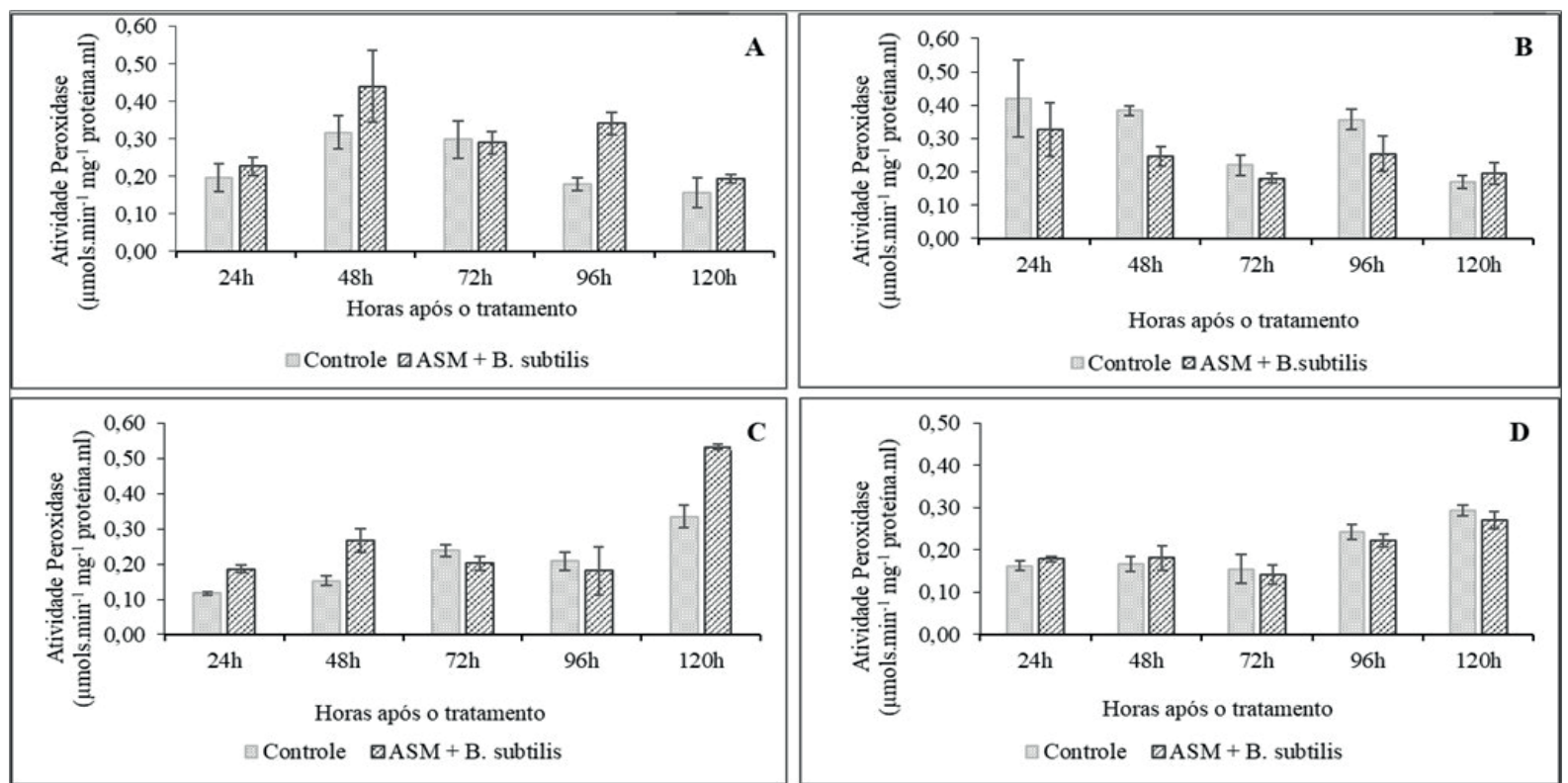

Figura 4. Atividade de $\beta$-1,3-glucanase em folhas de Heliconia psittacorum x sparthocircinata cv. Golden Torch cultivadas em sombreamento (A) e a pleno sol (B) e inflorescências cultivadas em sombreamento (C) e a pleno sol (D), tratadas com ASM + Bacillus subtilis e planta controle, coletadas com 24, 48, 72, 96 e 120 horas após o tratamento (HAT). As barras indicam o desvio padrão para as quadruplicatas.

parcelas que receberam o tratamento.

Nas inflorescências cultivadas em sombreamento, verificou-se que houve ativação da $\beta$-1,3-glucanase em plantas com tratamento e no controle. Para as plantas com tratamento observou-se que houve ativação de resistência, sendo o tempo de 120 HAT o de maior pico, indicando que o tratamento induziu resistência tardia (Figura 4C). A atividade da $\beta$-1,3-glucanase nas inflorescências cultivadas a pleno sol apresentou picos maiores às 96 e 120 HAT nas plantas com indutores (Figura 4D), apresentando resistência tardia assim como as plantas do ambiente sombreado.

A ativação da $\beta$-1,3-glucanase nas folhas e inflorescências evidencia que houve a ativação da resistência sistêmica adquirida, mesmo que esta tenha sido de forma tardia e em curto prazo. A resistência parcial configura-se como desvantagem para a planta, como afirma Bonaldo et al. (6), destacando que nesse tipo de resistência são necessárias reativações temporárias para que a planta esteja preparada para o ataque do patógeno. De acordo com Hammerschmidt (14), para que a planta alcance o estado de indução, é necessário um tempo após o contato dos 


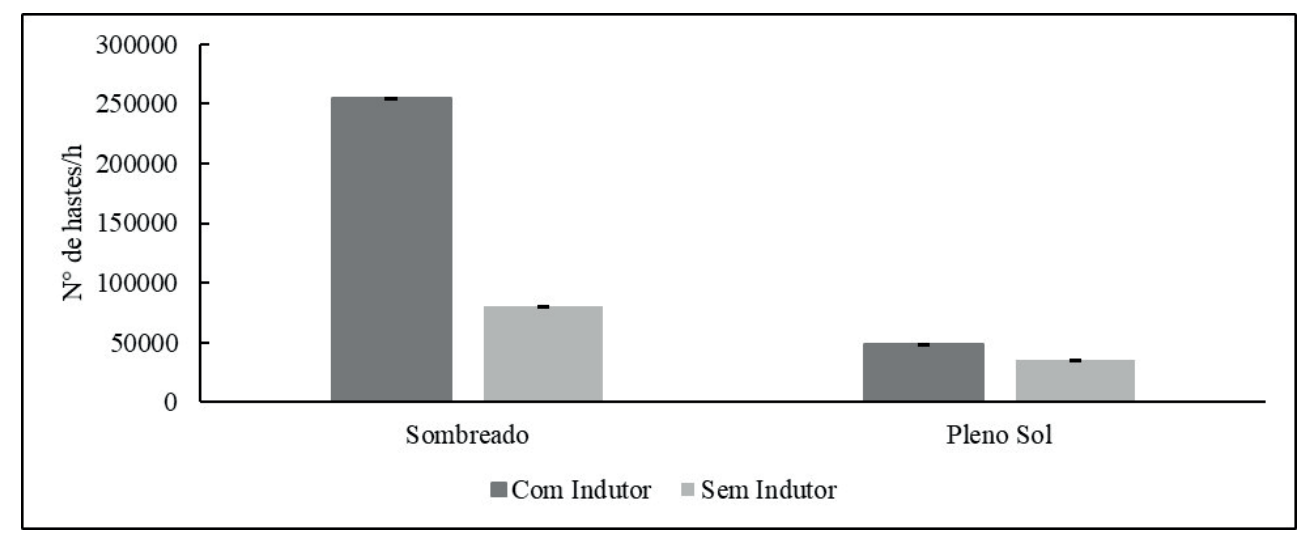

Figura 5. Produtividade total de hastes por hectare de Heliconia psittacorum x sparthocircinata cv. Golden Torch cultivadas em sombreamento (A) e a pleno sol (B), tratadas com ASM + Bacillus subtilis e planta controle do banco ativo de germoplasma de plantas ornamentais tropicais em Tangará da Serra - MT.

elicitores com a planta, considerando que a expressão dos genes não ocorre de imediato, leva algum tempo para que aconteça a expressão de resistência, seja dias ou semanas.

Dados encontrados por Kuhn (16) indicaram aumento na atividade de $\beta$-1,3-glucanase ao usar ASM, no entanto, ao utilizar um indutor biótico (Bacillus cereus), não observou aumento na atividade da mesma, diferindo dos resultados encontrados nesta pesquisa.

A ativação das proteínas relacionadas à patogênese, peroxidase $\mathrm{e}$ $\beta$-1,3-glucanase, estão associadas à Resistência Sistêmica Adquirida (RSA), tendo em vista que o ASM se relaciona com a RSA que é mediada pela rota metabólica do ácido salicílico (24).

Por outro lado, o uso de $B$. subtilis está relacionado à via de Resistência Sistêmica Induzida (RSI), que está vinculada à rota metabólica do ácido jasmônico e o etileno, contudo, a RSI não está associada ao acúmulo de proteínas relacionadas à patogênese (24).

Assim, a Resistência Sistêmica Adquirida (RSA) verificada neste estudo está associada ao aumento da atividade das PRPs, estas por sua vez, possibilitam acompanhar o estado de indução de resistência de plantas expostas aos patógenos (17).

Para produtividade foi possível verificar que as plantas tratadas com os indutores obtiveram acréscimo na produtividade, sendo de $68,65 \%$ nas plantas cultivadas em ambiente sombreado e $26,86 \%$ nas cultivadas a pleno sol (Figura 5). Além disso, a severidade da doença não afetou a produtividade de hastes florais.

$\mathrm{O}$ uso dos indutores de resistência influenciou na produtividade de hastes florais, isso pode ter ocorrido devido ao uso do B. subtilis e o ASM. As bactérias do gênero Bacillus sp., como $B$. subtilis fazem parte do grupo das bactérias promotoras de crescimento em plantas, estas por sua vez, permitem melhorar o crescimento das plantas e reduzir a dependência dos fertilizantes e defensivos agrícolas (2).

Estudo realizado por Zucareli et al. (30), ao utilizarem $B$. subtilis em associação, não encontraram diferença na produtividade do feijoeiro. Tavanti et al. (25) ao usar B. subtilis, obtiveram incrementos de produtividade na soja, resultado que corrobora com o presente estudo.

O uso do ASM também tem sido verificado quanto a sua eficiência sobre a produtividade dos cultivos. Rodrigues et al. (26), utilizando o ASM na produtividade de tomateiro industrial, não obtiveram ganhos na produtividade, mesmo tendo sucessivas aplicações durante o desenvolvimento da cultura.

Estudos evidenciam que o uso do acibenzolar-S-methyl (ASM) provocam alterações bioquímicas no metabolismo das plantas, levando a uma realocação de fotoassimilados para a defesa da planta (16). O fato de o ASM atuar na ativação da expressão de genes de efeito indutivo ligado às PRPs, pode desencadear um processo de competição, gerando maior gasto energético com as demais proteínas necessárias ao metabolismo primário, às atividades normais de crescimento e desenvolvimento da planta (5).

Assim, o uso dos indutores de resistência mostrou-se promissor na ativação do sistema de defesa das plantas contra fitopatógenos, devendo-se dar continuidade na pesquisa em busca de respostas sobre o seu efeito no controle de doenças e na ativação de diferentes mecanismos de defesa das plantas e na produtividade.

\section{AGRADECIMENTOS}

A Universidade do Estado de Mato Grosso Carlos Alberto Reyes Maldonado (UNEMAT).

\section{REFERÊNCIAS}

1. Abreu, S.P.M. Desempenho agronômico, características físico-químicas e reações a doenças em genótipos de maracujazeiro-azedo cultivados no Distrito Federal. 2006. 144p. Dissertação (Mestrado em Produção Vegetal) - Universidade de Brasília, Brasília, DF.

2. Adesemoye, A.O.; Torbert, H.A.; Kloepper, J.W. Plant Growth-Promoting Rhizobacteria Allow Reduced Application Rates of Chemical Fertilizers. Microbial Ecology, [S.I.], v.58, n.4, p.921-929, 2009.

3. Almeida, H.O.; Barbosa, M.D.O.; Marques, A.E.; Pereira, T.H.A.; Magalhães Júnior, M.J.; Tessarollo, N.G.; Abdelnoor, R.V. Enzimas marcadoras de indução de resistência diferencialmente reguladas em soja resistente e suscetível à ferrugem-asiática-da-soja. Pesquisa Agropecuária Brasileira, Brasília, v.2, n.47, p.163-172, 2012.

4. Athayde-Sobrinho, C.; Ferreira, P.T.; Cavalcanti, L.S. Indutores abióticos. In: Cavalcanti, L.S.; Di Piero, R.M.; Cia, P.; Pascholati, S.F.; Resende, M.L.V.; Romeiro, R.S. Indução de resistência em plantas a patógenos e insetos. Piracicaba: FEALQ, v.13. p.51-80, 2005.

5. Barros, R. Estudo sobre a aplicação foliar de acilbenzolar-S-metil para indução de resistência à ferrugem asiática em soja e cercosporiose em milho. Arquivos do Instituto Biológico, São Paulo, v.78, n.4, p.519-528, 2011.

6. Bonaldo, S.M.; Pascholati, S.F., Romeiro, R.S. Indução de resistência: noções básicas e perspectivas. In: Cavalcanti, L.S.; Di Piero, R.M.; Cia, P.; Pascholati, S.F.; Resende, M.L.V.; Romeiro, R.S. Indução de resistência em plantas a patógenos e insetos. Piracicaba: FEALQ, p.11-28, 2005.

7. Bradford, M.M.A rapid and sensitive method for the quantitation of microgram quantities of protein utilizing the principle of protein-dye binding. Analytical Biochemistry, [S.I.], v.72, n.1-2, p.248-254, 1976. 
8. Cantor, M.; Singureanu, V.; Denisa, H.; Erszebet, B. Heliconias-Novelties and applicability in floral art. Journal of Horticulture, Forestry and Biotechnology, [online], v.18, n.1, p.22-27, 2014.

9. Fernandes, C.F.; Moraes, V.C.P.; Oliveira, J.T.A. Determinação da atividade peroxidásica em cultivares de feijão-caupi (Vigna unguiculata) tratados com ácido salicílico. Porto Velho: Embrapa Rondônia, 2006. (Boletim de Pesquisa e Desenvolvimento, 41).

10. Ferreira, D.F. Sisvar: a computer statistical analysis system. Ciência e Agrotecnologia, Lavras, v.35, n.6, p.1039-1042, 2011.

11. Grigoletti Júnior, A.; Sônego, O.R. Principais doenças fúngicas da videira no Brasil. Circular Técnica EMBRAPA-CNPUV, Bento Gonçalves, p. 36, 1993.

12. Gurgel, L.M.S.; Coelho, R.S.B.; Oliveira, S.M.A.; Da Silva, R.L.X.; Rosa, R.C.T.; De Assis, T.C.; Andrade, D.E.G.T. Efeito de indutores de resistência no controle da antracnose do Bastão do Imperador (Etlingera Elatior). Anais da Academia Pernambucana de Ciência Agronômica, Recife, v.13, p.223-233, 2017.

13. Gurgel, L.M.S.; Coêlho, R.S.B.; Silva, R.L.X.; Oliveira, S.M.A.; Rosa, R.C.T.; Assis,T.C.; Andrade, D.E.G.T. Metodologia alternativa no manejo da antracnose pós-colheita em Heliconia rostrata. Pesquisa Agropecuária Pernambucana, Recife, v.19, n.19, p.20-24, 2014.

14. Hammerschmidt, R. Induce disease resistance: how do induced plants stop pathogense. Physiological and Molecular Plant Pathology, [online], v.55, n.2, p.77-84, 1999.

15. Kim, H.S.; Park, J.Y.; Choi, S.W.; Choi, K.H.; Lee, G.P.; Ban, S.J.; Lee, C.H.; Kim, C.S. Isolation and Characterization of Bacillus Strains for Biological control. Journal of Microbiology, [online], v.41, n.3, p.196-201, 2003.

16. Kuhn, J.O. Indução de resistência em feijoeiro (Phaseolus vulgaris) por acibenzolar-S- metil e Bacillus cereus: aspectos fisiológicos, bioquímicos e parâmetros de crescimento e produção. 2007. 140f. Tese (Doutorado em Agronomia) - Escola Superior de Agricultura Luiz de Queiroz, Universidade de São Paulo, Piracicaba, 2007.

17. Macagnan, D.; Romeiro, R.S.; Baracat-Pereira, M.C.; Lanna-Filho, R.; Batista, G.S.; Pomella, A.W.V. Atividade de enzimas associadas ao estado de indução em mudas de cacaueiro expostas a dois actinomicetos residentes de filoplano. Summa Phytopathologica, Botucatu, v.34, n.1, p.34-37, 2008.

18. Métraux, J.P. Systemic acquired resistance and salicylic acid: current state ofknowledge. European Journal of Plants Pathology, Berlin, v.107, n.1, p.13-18, 2001.
19. Nascimento, T.O.; Cardoso, V.L.J.L.; Silva, P.C.; Silva, C.G.; Dalbosco, E.Z.; Hiega, K.M.R.; Araújo, D.V. Doenças fúngicas em Helicônia no município de Tangará da Serra - MT. Revista MT Horticultura, [online], v.1, n.2, p.8-11, 2015.

20. Pandey, A.; Yadava, L.P.; Mishra; R.K.; Pandey, B.K.; Muthukumar, M.; Chauhan, U.K. Studies on the incident and pathogenesis of Colletotrichum gloeosporioides Penz. causes anthracnose of mango. International Journal of Science and Nature, [online], v. 3, n. 2, p. 220-232, 2012.

21. Poletto, I. Nutrição, sombreamento e antagonismo biológico no controle da podridão - de - raízes da erva - mate (Ilex paraguariensis $\mathbf{A}$. St. - Hill). 2008. 123f. Dissertação (Mestrado em Engenharia Florestal) Universidade Federal de Santa Maria, Santa Maria, 2008.

22. Rodrigues, A.C.P.S.; Camargos, I.M.F.; Araújo, D.O.; Duval, A.M.Q.; Rodrigues, T.T.M.S. Severidade da mancha bacteriana e produtividade de tomateiro industrial com o uso de Acilbenzolar-S-Metil em diferentes intervalos de aplicação e estrobilurina - cultivo de inverno. In: Seminário de Iniciação Científica, 5., 2016. Anais. Montes Claros: IFNMG, 2016. p.1-3.

23. Silva, J.M. Diversidade fúngica, seleção de genótipos e indução de resistência a Colletotrichum sp. em Heliconiaceae. 2018. 85f. Dissertação (Mestrado em Genética e Melhoramento de Plantas) - Universidade do Estado de Mato Grosso, Tangará da Serra, 2018.

24. Sticher, L.B.; Mauch-Mani, B.; Métraux, J.P. Systemic acquired resistance. Annual Review of Phytopathology, Lawrence, v. 35, n.1, p.235-270, 1997.

25. Tavanti, T.R.; Tavanti, R.F.; Galindo, F.S.; Simões, I.; Dameto, L.S.; Sá, M.E.D. Yield and quality of soybean seeds inoculated with Bacillus subtilis strains. Revista Brasileira de Engenharia Agrícola e Ambiental, Campina Grande, v.24, n.1, p.65-71, 2020.

26. Valderrama, P.; Fabiane, M.; Clemente, E. Efeito do tratamento térmico sobre a atividade de peroxidase (POD) e polifenoloxidase (PPO) em maçã (Mallus comunis). Food Science and Technology, Campinas, v.21, n.3, p.321-325, 2001

27. Van Loon, L.C.; Bakker, P.A.H.M.; Piterse, C.M.J. Systemic resistance induced by rhizosphere bacteria. Annual Review of Phytopathology, [S.I.], v.36, n.1, p.453-483, 1998

28. Vogelsang, R.; Barz, W. Purification, characterization and differential hormonal regulation of a $\beta-1,3$ glucanase and two chitinases from chickpea (Cicer arietinum L.). Planta, [S.I.], v.189, n.1, p.60-69, 1993.

29. Warumby, J.F.; Coelho, R.S.B.; Lins, S.D.O. Principais doenças e pragas em flores tropicais no Estado de Pernambuco. Recife: Sebrae, p.98, 2004.

30. Zucareli, C.; Barzan, R.R.; Silva, J.B.D.; Chaves, D.P. Associação de fosfatos e inoculação com Bacillus subtilis e seu efeito no crescimento e desempenho produtivo do feijoeiro. Revista Ceres, Viçosa, v.65, n.2, p.189-195, 2018. 